\title{
Child Sexual Offenders Typologies: An Exploratory Profile Model using Multiple Correspondence and Cluster Analysis of Portuguese Convicted Offenders Sample
}

\author{
Ricardo Ventura Baúto $\mathbb{D}^{\mathrm{a}, \mathrm{b}, \mathrm{c}}$, Jorge Cardoso $\mathbb{D D}^{\mathrm{b}}$, and Isabel Leal (iD) \\ aLaboratório de Ciências Forenses e Psicológicas Egas Moniz (LCFPEM) Campus Universitário, Quinta da \\ Granja, Monte de Caparica Caparica 2829-51, Portugal; 'Laboratório de Psicologia Egas Moniz (LabPSI), \\ Centro de Investigação Interdisciplinar Egas Moniz (CiiEM), Instituto Universitário Egas Moniz (IUEM), \\ Campus Universitário, Quinta da Granja, Monte de Caparica, Caparica 2829-511, Portugal; 'William \\ James Center for Research, ISPA—Instituto Universitário, Rua Jardim do Tabaco, Lisboni 34, 1149-041, \\ Portugal
}

\begin{abstract}
Child Sexual Abuse (CSA) is not a recent phenomenon. However, it increased visibility in Portugal in 2002, when a news piece raised suspicions about numerous public figures. Since then, there has been an upward trend in complaints and has stabilized in recent years. Nevertheless, even though the research emerging, it presents gaps in the characteristics and modus operandi of the child sex offenders in the Portuguese context.

This article presents an exploratory study, where 66 case reports of inmates in Portugal (Lisbon District) were convicted for CSA crimes recorded in the last ten years.

We used the Multiple Correspondence Analysis and Cluster Analysis as statistical procedures, focusing on the dynamics of the offense, context, number of victims, relationship, and characteristics of the offense. With this analysis, we identified four distinct profiles, which occurs with both techniques. In addition, we found differences regarding the use of aggressivity and/or treating during or after the offense, nature of abuse and introduced the crime admission as an active variable, with contributions to the model definition. According to these results and international literature, we defined our groups in four types: Regressed, Indiscriminate, Inadequate, and Violent.

We discuss our results based on the international models and demonstrate affinities with them.
\end{abstract}

\section{KEYWORDS}

Child sexual abuse; sexual offenders; multiple correspondence analysis; criminal profiling

\section{Sexual offending models}

Child Sexual Abuse (CSA) can leave profound consequences for its victims and harms the whole community. In Portugal, the crime obtained a particular projection from 2002, when a journalistic investigation released details that would involve several public figures (e.g., showbiz, politics) in a child sexual abuse scandal. The process would become known, such as the Casa Pia

CONTACT Ricardo Ventura Baúto rbauto.Icfpem@egasmoniz.edu.pt E Laboratório de Ciências Forenses e Psicológicas Egas Moniz (LCFPEM), Campus Universitário, Quinta da Granja, Monte de Caparica, Campus Universitário, Quinta da Granja, Monte de Caparica 2829-511, Portugal 
Process, the name of Childcare Institution, which would have happened the abuse situations (cf. BBC News, 2010, September 3). Since then, there has been an increase in the number of complaints and has, in recent years, stabilized. In 2018 there was a decrease of $10.8 \%$ of complaints, falling to 836 reported cases in Portugal (Sistema de Segurança Interna, 2018, p. 9).

In the Scientific field, there are many definitions of CSA, most of which focus on the nature of the acts performed, which may be through direct physical contact or exposure to sexual content (e.g., Veenema, Thornton, \& Corley, Mathews \& Collin-Vézina, 2019; Veenema et al., 2015a). In this study, we use the definition of the World Health Organization "Child sexual abuse is the involvement of a child in sexual activity that he or she does not fully comprehend, is unable to give informed consent to, or for which the child is not developmentally prepared and cannot give consent, or that violates the laws or social taboos of society." Child sexual abuse evidenced activity between a child and an adult or another child who by age or development is in a relationship of responsibility, trust or power, the activity being intended to gratify or satisfy the needs of other person's needs of abuse may include but is not limited to: the inducement or coercion of a child to engage in any unlawful sexual activity; the exploitative use of a child in prostitution or other unlawful sexual practices; the exploitative use of children in pornographic performance and materials" (World Health Organization, 1999, p. 15).

The CSA may be subdivided according to the existence or absence of contact by the offender. The first refers to the sexualized touch on the child's body, which may occur sexualized kisses and objects for digital stimulation (Chopin \& Caneppele, 2019; Finkelhor, 1984, 1994; Howells, 1994; Ward \& Hudson, 2001). Regarding the absence of contact, this relates to voyeurism exhibitionism and pornography exposure behaviors, for example. The child may not be a direct actor in action (Finkelhor, 1994; Finkelhor, Cuevas \& Drawbridge, Finkelhor et al., 2016). On the other hand, contactless sexual abuse is often associated with the pre-act process, where the perpetrator fantasizes about contact with children, starting to get sexually aroused by the idea.

Over the years, research has also deepened comprehensive models of CSA, which have gained higher expression through the soundness of their arguments, namely the Finkelhor Precondition Model (Finkelhor, 1984), the Marshall and Barbaree Integrated Model (Marshall \& Barbaree, 1990) and the Hall and Hirschman Quadripart Model (Hall \& Hirschman, 1992). Regarding cognitive distortions as an explanation for the offender's functioning, the Abel et al. (1984)model emerged, which would be deepened and redirected in the approach through other models such as Implicit Theories (Ward, 2000; Ward \& Keenan, 1999) or the Pathways Model (Ward \& Siegert, 2002). It is required to detail each and how, in some cases, models coexisted and emerged in parallel, emphasizing different variables. As mentioned, one of 
the first models used to describe CSA offending was the Finkelhor Preconditions Model. Finkelhor (1984) developed a multifactorial model that shaped the first attempt to comprehensively explain which factors are inherent in sexual assault on children. The author systematizes its Model in four essential preconditions: a) emotional congruence, b) sexual arousal, c) blockage, d) disinhibition. Finkelhor (1984) also states that they may emerge differently but will always trigger these preconditions. Several authors (Gannon et al., 2012; Howells, 1994; Ward \& Hudson, 2001; Ward et al., 2006; Ward \& Siegert, 2002) mentioned the simplicity and ability to systematically relate the different factors associated with sexual abuse behavior to children. Several years later, Marshall and Barbaree (1990) conceptualized an integrated model, where individuals subject to adverse situations (e.g., inadequate socioeconomic resources during childhood; inconsistent parenting; direct or indirect exposure to violence) physical and/or sexual) are more likely to develop distorted perceptions of their internal models of functioning and relationship, specifically aggression and sex. From this perspective, an essential element in the psychosexual development of male adolescents is learning to distinguish between aggressive and sexual impulses and the control of aggressive tendencies during sexual experiences. These authors suggested that sexual crimes, such as CSA, result from a diverse set of interacting factors, converging at a particular point in time and deriving from the passage to the act. Some elements are highlighted as causal factors, namely experiences regarding biological processes, cultural beliefs, gender roles, and attitudes about sex. Although the Model is detailed at the level of the psychological functioning vulnerabilities of the offenders, it does not include a set of explanatory variables that support the development of pathways related to sexual aggression, rather than any other antisocial behavior (Ward \& Hudson, 2001; Salerno, 2014).

Another model approach was the Quadripartite Model of Hall and Hirschman (1992). This Model has four components, sexual arousal or activation of inadequate physiological nature, inaccurate cognitions or distortions that allow the perpetrator to justify the action, effective lack of control, and deficits in personality structure. The main idea of this Model suggests that each of these factors underlies the motivational precursors that lead to the possibility of these individuals sexually abusing a child (Ward \& Beech, 2006). Hall and Hirschman (1992) reported that sexual activation in isolation does not constitute a risk of the act, but they can trigger aggressive behaviors when combined with personality disorders and lack of control at the affective level. Authors also refer that the passage to the act may be inhibited or otherwise facilitated, based on the experiences lived and learned in the socialization process. 
Abel et al. (1984) present one of the first models of cognitive distortion. Authors divided into those that focus on cognitive processes after engaging in sexually deviant behaviors (e.g., Abel et al., 1989); and those built around the cognitive structures supposed to precede and maintain aggression (e.g., Ward, 2000). These authors suggest that a process of sexual development deprived of an adequate understanding of social norms and expectations regarding normative sex behaviors may promote deviant sexual responses. They further emphasize that the individual, in the front of these conditions, develops a split consciousness between what is socially accepted as normative and, on the other hand, his sexual preferences. Later Ward $(2000,2009)$ states that deviant sexual arousal, deficits in relationships of intimacy, affective incongruence, and cognitive distortions; claim to be relevant in the risk of developing inappropriate sexual behavior with a minor. In this way, sex offenders can develop distortions in their sexual scripts, creating dysfunctional relationship schemes resulting from inappropriate or early sexual experiences where periods of rejection, disappointment, or loneliness can lead to learning deviations (Ward, 2000; Ward \& Siegert, 2002). At the same time, Ward and Siegert (2002)presented a parallel approach, designated Pathways Model that proposed interaction between clinical problems and some vulnerability factors: emotional regulation deficits, deviant sexual scripts, intimacy/social skills deficits, and antisocial cognitions.

Ward and Beech (2016)presented a new approach to the integrated Theory of Sexual Abuse. According to the authors, for an integrated reading of human behavior to exist, four levels of analysis must be present: etiological, where environmental and genetic factors are understood, brain mechanisms, neuropsychological analysis (concerning the psychological systems associated with the perception and production of language), and level of phenomenological and/or psychopathological analysis (e.g., deviant sexual arousal). This Theory thus warns of the multifactorial aspect of sexual aggression and includes different causal sources. Furthermore, the same authors argue that the etiological basis of sexually abusive behavior is a combination of genetic and environmental factors.

\section{Typologies of child sexual abuse offenders}

Research into typologies of sexual offenders began in the 1960s (cf. Mohr, Turner \& Jerry, 1964), and a few years later, with research focused on a specific group of sexual offenders, the child molesters (Laws \& Marshall, 2003; Liang \& Hu, 2018; Lyons \& Romano, 2019; Saramago et al., 2020; Soeiro, 2009). This kind of study has classified offenders according to several criteria issues, such as demographics, personal and social characteristics (Goodwill \& Alison, 2007; Goodwill et al., 2009, 2016, 2013; Rebocho \& Gonçalves, 2012; Safarik et al., 2002; Saramago et al., 2020), nature of offenses, the relationship between 
offender and their victims (Waterhouse et al., 2016), victim characteristics, and other information's (Liang \& Hu, 2018; Robertiello \& Terry, 2007). For example, Terry (2006)as cited in Robertiello \& Terry, 2007) identified a set of characteristics common to subjects who sexually abuse children, namely poor social skills, low self-esteem, feelings of inadequacy, worthlessness, and vulnerability. These authors also suggested previous frustrating relationships with adults, along with self-image and performance problems. Although there is a diversity of authors who develop research on the subject, there are few who, over the last few decades, have advanced to extended data analysis, seeking to generate taxonomic models. Therefore, it is necessary to look at models (in some cases over 30 years old) to reference comprehensive and typological models.

In the 1980s, authors such as Knight, Rosenberg \& Shneider (1985)presented descriptive models about the characteristics/typologies of child sexual offenders. Simon and Gagnonlectured the research of other authors (cf. Cohen et al., 1969; Burgess et al., 1978; Groth \& Birnbaum, 1978; Groth et al., 1982) who had analyzed the characteristics of other types of sexual offenders. The authors concluded that the perspective of a model based on the Fixated-Regressed dichotomy (cf. Groth \& Birnbaum, 1978; Groth et al., 1982) would, in their view, be the most acceptable explanation. This perspective refers to the motivation for perpetration as a differentiating element among offenders, considering two issues (cf. Burgess et al., 1978; Groth \& Birnbaum, 1978; Groth et al., 1982). Concerning the fixed offenders (Groth \& Birnbaum, 1978), described as preferred, they tend to have a persistent, continuous, and compulsive attraction to children (Groth et al., 1982; Terry \& Tallon, 2004). There tends to be a higher frequency of abuse and pedophilia diagnosis (Terry \& Tallon, 2004). More recently, a study by Camperio Ciani et al. (2019)showed that acquired paraphilic behavior represents a small proportion (although relevant) in cases of sexual abuse. This kind of offender has no relationship with the victim, seeking to establish a close relationship and trust.

In parallel, another group of offenders was described as regressed (Burgess et al., 1978). These offenders are not primarily motivated by children's physical or psychological characteristics but by sexual gratification and access to victims (Lehmann et al., 2014). It could identify children as an alternative to adults and seek to establish sexual behaviors closer to them than adults, seeking out with adults. In this group, the offenders who committed incest are found (Lanning, 2010), rarely resorting to physical strength, resorting to the trust inherent in the preexisting relationship (Lehmann et al., 2014). Groth and Burgess (1977) had already mentioned the relevance of criminal behavior as being present (in several cases), a diverse criminal history (e.g., crimes against people, property ...). The FBI would extend Groth's typology levels to include seven subgroups of criminals (see Table 1). 
Table 1. The FBI typologies of the child molester (Lanning, 2010).

\begin{tabular}{|c|c|}
\hline Type of offender & Characteristics of offenders \\
\hline \multicolumn{2}{|l|}{$\begin{array}{l}\text { Situational } \\
\text { Offenders }\end{array}$} \\
\hline Regressed & $\begin{array}{l}\text { Offenders have poor coping skills, easily accessible target victims, and abuse children to } \\
\text { substitute for adult relationships. }\end{array}$ \\
\hline $\begin{array}{l}\text { Morally } \\
\text { Indiscriminate }\end{array}$ & $\begin{array}{l}\text { Offenders do not prefer children over adults and use children (or anyone accessible) for their } \\
\text { interests (sexual and otherwise). }\end{array}$ \\
\hline $\begin{array}{l}\text { Sexually } \\
\quad \text { Indiscriminate }\end{array}$ & $\begin{array}{l}\text { Offenders are mainly interested in sexual experimentation and abuse children out of } \\
\text { boredom. }\end{array}$ \\
\hline Inadequate & $\begin{array}{l}\text { Offenders are social misfits who are insecure, have low self-esteem, and see relationships with } \\
\text { children as their only sexual outlet. }\end{array}$ \\
\hline \multicolumn{2}{|c|}{ Preferential Offenders } \\
\hline Seductive & $\begin{array}{l}\text { Offenders "court" children and give them much affection, love, gifts, and enticements in order } \\
\text { to carry on a "relationship." }\end{array}$ \\
\hline Fixated & $\begin{array}{l}\text { Offenders have poor psychosexual development, desire affection from children, and are } \\
\text { compulsively attracted to children. }\end{array}$ \\
\hline Sadistic & $\begin{array}{l}\text { Offenders are aggressive, sexually excited by violence, target stranger victims, and are } \\
\text { extremely dangerous. }\end{array}$ \\
\hline
\end{tabular}

More recently, some authors found differences between intra and extrafamily offenders. For example, Seto, Babchishin, Pullman and McPhail (2015) conducted a meta-analysis comprising 78 studies comparing the two types. The authors concluded that intrafamilial individuals tended to score less in antisocial behaviors and deviant sexual interests when compared to extrafamilial aggressors. In addition, beliefs and attitudes that legitimized violence emerged with a more significant impact on extra-family aggressors.

Other authors (e.g., Wortley \& Smallbone, 2006) described a range of offenders motivated by opportunity and/or as a way of externalizing aggressive and controlling instrumental behaviors (Bennell et al., 2001; Scarpazza, Pellegrini, et al., 2018). It can also verify an additional element to the previously described group, where sexual aggression appears to injure the victim, where aggression can be eroticized (Bennell et al., 2001; Canter et al., 1998; Schaaf et al., 2019). Knight and Prentky (Knight \& Prentky, 1990)proposed another classification system, the MTC: CM3, based on two axes (see Table 2).

The last decades of scientific research have allowed the creation of criminal profiles that include two large groups: sexual abusers of minors and rapists (Laws \& Marshall, 2003; Liang \& Hu, 2018; Lyons \& Romano, 2019; Soeiro, 2009). In addition, elements such as sociodemographic characteristics, psychopathology (including paraphilias such as pedophilia) and the respective abusive dynamics have emerged with predictive purposes and the consequent

Table 2. MTC: CM3 classification system (Knight \& Prentky, Knight \& Prentky).

\begin{tabular}{ll}
\hline Axis & \multicolumn{1}{c}{ Description of axis measurement } \\
\hline $\begin{array}{l}\text { Axis I - Measures the level of social } \\
\text { competence of the offender }\end{array}$ & $\begin{array}{c}\text { Assesses the extent to which the offender is fixated with children } \\
\text { (on a continuum) }\end{array}$ \\
$\begin{array}{l}\text { Axis II - Meaning of the contact (sexual and } \\
\text { interpersonal) }\end{array}$ & $\begin{array}{l}\text { Assesses the amount of contact the offender has with children } \\
\text { (e.g., exclusively involved with } \\
\text { extra-familial children, abuses own children) }\end{array}$ \\
\hline
\end{tabular}


prevention of recurrence (Safarik et al., 2002; Goodwill \& Alison, 2007; Goodwill \& Alison, 2007; Goodwill et al., 2009, 2013; Rebocho \& Gonçalves, 2012; Goodwill et al., 2016; Ciania, Scarpazza, Covelli \& Battaglia; Ciani, et al., 201920192019). Another element is the relationship between the aggressor and his victims (Waterhouse et al., 2016) and the characteristics of the victims (Liang \& Hu, 2018; Robertiello \& Terry, 2007; Stephens et al., 2018) were considered to establish standards for the exercise of sexual violence by these kinds of offenders.

The main purpose article is to present an exploratory model of child sexual offenders typologies, from a convicted sample, sentencing with prison in Portugal, identifying differences between groups that allow us to conclude about their heterogeneity, and comparing with the models recognized at an international level. In addition to the analysis of criminal behavior, it intended to introduce a cognitive variable related to subjects' perspective about crime, namely the admission of crime and its self-criticism (with critical resonance or minimization/legitimation), paving the way for future research that relates attitudes and behavior with intervention programs.

\section{Method}

This study uses a mixed-method, which performed a content analysis of cases of subjects convicted by CSA), followed by quantitative analysis, performed through the Multiple Correspondence and Cluster Analysis. Concerning content analysis, this was used to extract the information needed to define a proposal for a CSA offenders typologies model. The data collected relate to each of the convicted subjects, and a table of criteria was created based on information associated with the crime scene, victim characteristics, offender characteristics and modus operandi. This information was coded to introduce the criteria in a dichotomous way $(0=$ absence; $1=$ presence $)$.

\section{Sample}

This research consists of a retrospective study based on the re-analysis of 72 closed criminal cases of sexual abuse in Portugal between 2014 and 2019. The sample was based on 72 inmate subjects convicted for crimes of child sexual abuse (CSA). The authors used a Portuguese Criminal Law Typification [i.e., Minors Sexual Abuse and Sexual Abuse of Dependent - articles 161 and 162 of Portuguese Criminal Code]. All subjects were considered mentally capable by the Judicial Courts. Only men were included in the sample, with ages between 18 and 68 years $(45.5 \pm 9.83)$. 


\section{Procedure}

All information has been collected concerning privacy and individual personal data. This study is confirmed with the Declaration of Helsinki and was approved by Portuguese Authorities (General Directorate of Prison Services and Social Reintegration, authorization No. 154/DSOPRE of 09-09-2013) for access to the criminal registry of inmate subjects convicted by sexual abuse in Lisbon District.

All the cases were collected, demographic variables, personal and social characteristics (Safarik et al., 2002), nature of offenses, and the relationship between offenders and their victims (Waterhouse et al., 2016) and victim characteristics. In addition, concerning the information about the offender was included the criminal records, sociodemographic variables (age, previous convictions, marital status, qualifications, employment situation), the relationship with the victim(s), history of mental health, and consumptions (Table 3 ).

The information about victims includes sociodemographic variables such as age, sex, relationship with the offender, and physical and/or mental problems. Authors also collected data about modus operandi with particular focus on the dynamics of the offense, context, the number of victims, characteristics of the offense (i.e., penetrative, or non-penetrative offending, aggressivity, and/or threat, grooming and/or gratification, use of condom and ejaculation). Only in some cases were collected all the information about the last two variables. The

Table 3. Variables and categories relating to the offense (frequency, valid cases, and percentage).

\begin{tabular}{lccc}
\hline Variables and categories & Frequency & $\mathrm{N}$ & $\%$ \\
\hline Sexual stimulation & & 66 & \\
No sexual stimulation & 6 & & 9.1 \\
Fisting and/or objects introduction & 2 & & 3.0 \\
Masturbation and sexualized touch (inc. non- penetrating & 39 & & 59.1 \\
friction) & & & 12.1 \\
Masturbation and porn preview & 8 & & 9.1 \\
Fisting. introduction and masturbation & 6 & & 7.6 \\
$\quad$ Introduction, masturbation and porn preview & 5 & 66 & \\
Penetrative sexual intercourse & & & 12.1 \\
Without penetration & 8 & 6.1 \\
Oral penetration & 4 & & 30.3 \\
Vaginal penetration & 20 & & 13.6 \\
Anal penetration & 9 & 10.6 \\
Oral and vaginal penetration & 7 & & 13.6 \\
Oral and anal penetration & 9 & & 12.1 \\
Anal and vaginal penetration & 8 & & 1.5 \\
Oral. vaginal and anal penetration & 1 & 58 & 48.3 \\
Aggressivity and/or threatening victims & & & 1.7 \\
Without aggression or threat & 28 & & 15.5 \\
Physical aggression & 1 & & 13.8 \\
Physical aggression threat & 9 & & \\
Threat (various) & 8 & & 73 \\
Aggression and threat & 12 & & \\
Grooming and/or gratification & & & \\
No & 46 & & 27 \\
Yes & 17 & & \\
\hline
\end{tabular}


local and frequency of offense were also contemplated. Once those individual records analyzed were from inmate subjects, authors also collect information about the accompaniment of Prison Services, which reports the perspectives of these inmates regarding the crime, such as self-criticism and legitimisation/ minimization. Finally, five cases were subsequently excluded regarding those variables as the information available was not complete enough. The final database thus included 66 cases. It should be noted that with an average of 280 inmate subjects convicted in Portugal for this criminal type, the present sample $(\mathrm{N}=66)$ leads to a margin of error of $8.84 \%$ and a confidence level of $90 \%$.

\section{Analysis}

\section{Data categories}

To analyze the data with the objective of different determinate groups of CSA, we define two phases, data collection/processing and statistical analysis. As a preparatory phase to the statistical treatment, the information collected was reduced by categories and included in the dataset of $\mathrm{IBM}^{\bullet}$ SPSS $^{\circ}$ Version 25. We used the FBI Child Molesters Profile Model (Lanning, 1986,, Lanning, 2010) to define the variables since it is the same that has already been used [in the only study of its kind carried out] in Portugal by the Judiciary Police (Soeiro, 2009).

\section{Multiple correspondence analysis (MCA)}

Concerning statistical analysis, we used the multiple correspondence analysis (MCA), which allows analyzing the pattern of relationships in the categorical dependent variable and obtaining a formal correspondence analysis on the indicator matrix (Abdi \& Valentin, 2007). This technique provides a representative model of a high number of variables, prospecting the reduction of the construct (i.e., factors) (Di Franco, 2016). Di Franco (2016, p. 1307) describes the merits of MCA as having "excellent descriptive powers since it allows one to examine the simultaneous interaction of many variables by exploring their direct links (...) is very sensitive to analyses of the relationships between cases and between variables." We analyzed the profiles as coordinates, considering a multi-dimensional model, where sub-optimal space is distinguished, maximizing inertia (dispersion of calculated distances between points set), corresponding to the variation explained (Di Franco, 2016). A higher number of cases could be creating a more robust model with better fit results, but it will not be a mandatory decision. According to the values analyzed, it is distinguished whether they directly contribute to the formation of factors. At the same time, supplementary categories were used (which do not contribute directly to the creation of factors but may be relevant to their interpretation) 
(Abdi \& Valentin, 2007; Di Franco, 2016). These variables derive from the MCA analysis performed but without explanatory value that directly contributes to the definition of the profile. However, given their descriptive significance, they are included to illustrate the characteristics of the subjects in this group.

Finally, it should be noted that a minimum number of cases was not defined to be carried out for this analysis, since according to Di Franco (2016), there are no clear guidelines against the minimum number of cases necessary to use MCA.

\section{Inertia analysis of MCA}

To evaluate the quality of dimensions and decide the appropriate number of dimensions to configure the space under analysis, we verified the variance (eigenvalue variance explained by each dimension) and inertia (variance in relative terms). From the analysis of eigenvalues and dimension inertia (Table 4), we verified that the first two dimensions have eigenvalues and higher inertia values.

Regarding observing the graphical representation of the variance of the dimensions (Figure 1), two explanatory axes (dimensions) were selected, which explain $59.5 \%$ of the inertia, where a proportion of variation explains for dimension $1=33.5 \%$ and dimension $2=25.9 \%$. Thus, it was possible to distinguish two different groups with two different typologies with MCA results that resulted in four profiles.

In parallel, with the resource of centroid analysis, we verified that the first group contained two profiles where the offender had some tight linkage with them, victims. In the second group, two different profiles related once again to the relationship of offenders with their victims, namely known and unknown

Table 4. Inertia analysis of MCA includes the variables selected in the previous phase, with a factorial weight equal to or greater than the explained average. Thus, when comparing factor weights of identified dimensions, it is possible to decide on their final distribution.

\begin{tabular}{lccc}
\hline Dimension & & & \\
\hline & 1 & 2 & Mean \\
Number of victims & .447 & .124 & .286 \\
Marital status & .421 & .200 & .310 \\
Relationship with victims & .64 & .445 & .542 \\
Abusive Sexual Stimulation & .253 & .357 & .350 \\
Penetrative sexual intercourse & .357 & .390 & .373 \\
Aggressivity and/or threating victims & .126 & .566 & .346 \\
Criminal history & .444 & .110 & .277 \\
Crime admission & .370 & .950 & .210 \\
Justification and/or banalization & .240 & .287 & .155 \\
Grooming and/or gratification & .332 & .210 & .176 \\
Inertia & 3.35 & 2.59 & 2.97 \\
& 1 & 5 & 3 \\
Mean & .335 & .260 & .297 \\
\hline
\end{tabular}




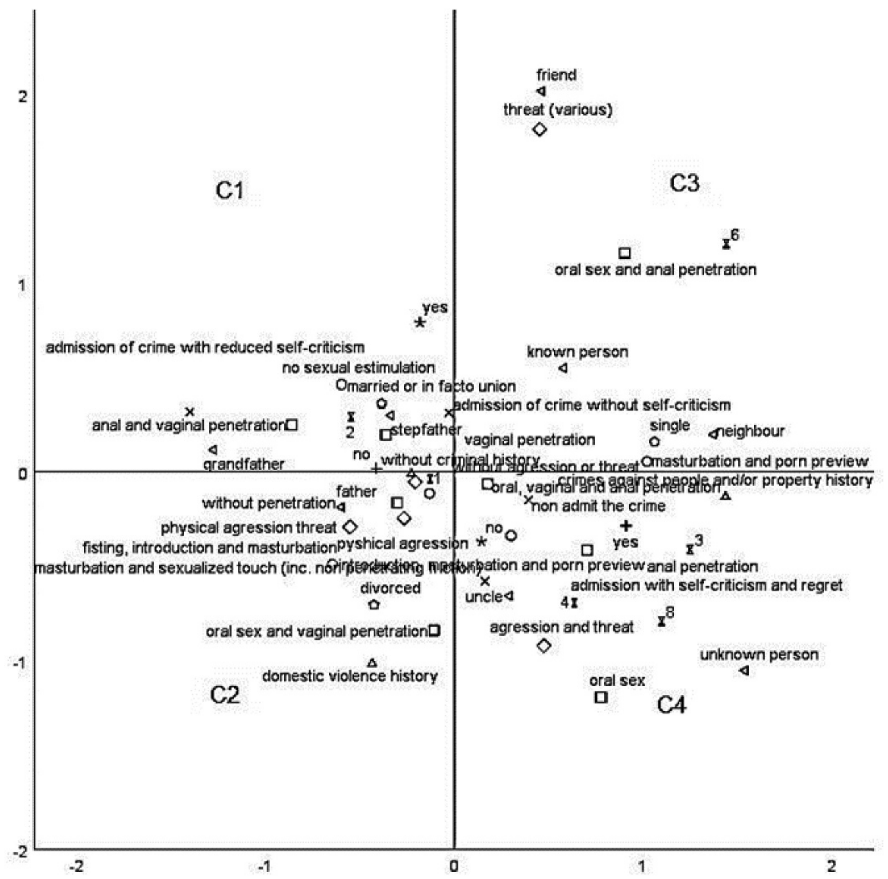

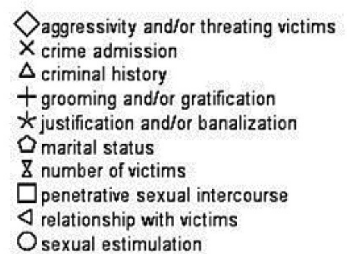

Figure 1. Multiple correspondence analysis maps with dimensional themes divided by four clusters according to the factor weights presented in the inertia table. Although there are four clusters, it appears that two large dimensions are separating them. The relationship with the victim seems to be the differentiating element.

offenders. However, we could identify other issues that provide better knowledge about interpersonal behavior and offending when we analyze every ten active variables and each category. It is still relevant to refer that in our study, we also collected more than nine variables. After analyzing the dimension scores and the number of missing information in criminal records, we concluded that those variables do not be helpful to produce a good fit model in our sample. We opted to include them as supplementary variables, then assign a better description of our proposal model since they are conceptual relevant for criminal behavior (see Table 5).

We distinguish four groups, which one with similar discriminate characteristics. In the first group, the authors included different dynamics, namely, if the offenders' recorded victims, appealed to online seduction, had used a condom, and ejaculated (and how) during the offending. The second group indicates two relevant variables in the offending context, namely the place and frequency that occurred. Other relevant groups contemplate mental and biological victim's characteristics (mental illness, psychopathology, and sex). Finally, offender characteristics, non-included latent variables, but relevant for a comprehensive model, we analyzed the alcohol consumptions during abuse and mental illness or substance consumptions. Based on its 
Table 5. Supplementary variables and categories (frequency. valid cases, and percentage) derive from the information collected. Although their factor weights indicate that they do not contribute to the definition of the Model, they allow it to be illustrated and differentiated, so they were included in the final Model proposed.

\begin{tabular}{|c|c|c|c|}
\hline Supplementary variables and categories & Frequency & $\mathrm{N}$ & $\%$ \\
\hline \multicolumn{4}{|l|}{ Dynamics } \\
\hline Recording victims & & 66 & \\
\hline No & 63 & & 95.5 \\
\hline Yes & 6 & & 4.5 \\
\hline Online seduction & & 66 & \\
\hline No & 63 & & 95.5 \\
\hline Yes & 3 & & 4.5 \\
\hline Condom use & & 66 & \\
\hline No & 52 & & 96.3 \\
\hline Yes & 2 & & 3.7 \\
\hline Ejaculation during abuse & & 66 & \\
\hline Without ejaculation & 6 & & 10.7 \\
\hline Ejaculation inside victims & 20 & & 35.7 \\
\hline Ejaculation out of the victims & 21 & & 37.5 \\
\hline Both & 9 & & 16.1 \\
\hline \multicolumn{4}{|l|}{ Context } \\
\hline Place & & 66 & \\
\hline Offenders home & 34 & & 51.5 \\
\hline Street/vehicle/other & 6 & & 9.5 \\
\hline Victims and offenders home & 23 & & 36.5 \\
\hline Frequency & & 66 & \\
\hline Just once & 3 & & 6.5 \\
\hline At least three times & 9 & & 19.6 \\
\hline At least five times & 3 & & 6.5 \\
\hline At least one time for a month & 18 & & 39.1 \\
\hline At least one time for a week & 9 & & 19.6 \\
\hline Daily or almost diary & 4 & & 8.7 \\
\hline Just once & 3 & & 6.5 \\
\hline Victims characteristics & & 66 & \\
\hline Sex of victims & 13 & & 19.7 \\
\hline Male & 48 & & 72.7 \\
\hline Female & 5 & & 7.6 \\
\hline Alcohol consumption & & 66 & \\
\hline Yes & 46 & & 71.8 \\
\hline No & 18 & & 28.1 \\
\hline
\end{tabular}

graphical interpretation, representative of the distribution of fusion coefficients, it concludes that the most significant decrease corresponds to four clusters, and from this location, the distances between coefficients tend to decrease more sharply. Thus, this result reinforces the solution obtained through MCA (see Figure 1).

\section{Hierarchical cluster analysis}

After identifying the groups of offenders using MCA, we proceeded to their more detailed characterization, identifying their distinctive elements, through Cluster Analysis (CA). The Hierarchical Cluster analysis was first resorted to by the Ward Method, followed by the Furthest Neighbor Method. Hierarchical Cluster Analysis is based on the idea that objects are more related to close 


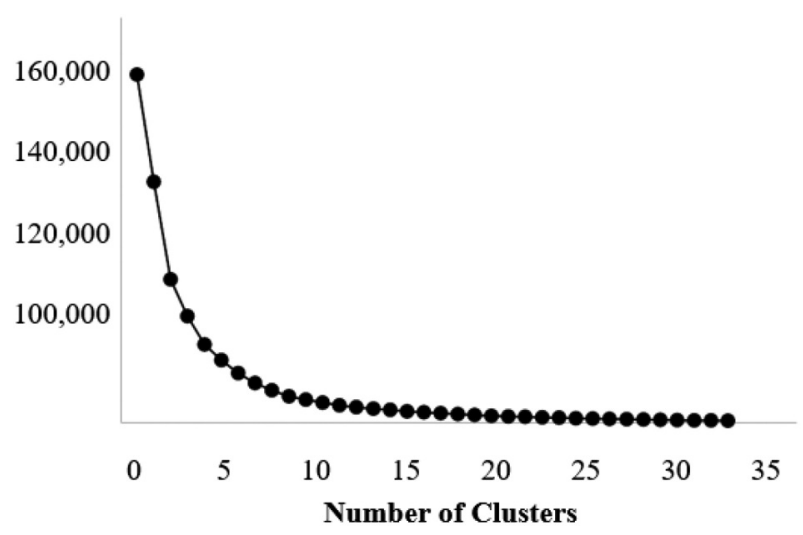

Figure 2. Hierarchical Cluster Analysis with the Ward Method choosing the pair of clusters based on the optimal value of an objective function, graphically verifying that the Model has four clusters.

objects than distant objects. Based on the algorithm, these objects form clusters based on their distance from each other. Thus, the Cluster is defined based on the maximum distance needed to define and hierarchize as relationships between objects, creating unique sets. Furthermore, the different analysis methods allow for a partitioning that allows the definition of the necessary clusters and identification of outliers, which serve as additional clusters based on the theoretical construct.

After this, we attempted to perform a transfer of individuals to the nearest Cluster, performed through the K-Means Cluster Analysis, thus verifying the above (i.e., the number of clusters). Finally, we verified that it was necessary to conduct subsequent analyses, refining the results perspective and checking their stability to produce a good fit result (Table 4). With a graphical analysis of MCA, constituted with a minimum of two factorial axes, it is possible to project a model regarding variable-categories estimated positions of dots, identify the structure of relationships (Abdi \& Valentin, 2007; Di Franco, 2016) and the number of groups.

From results with HCA (both methods), where was concluded, when compared with MCA results, this Model presents four clusters, the same number previously founded (see Figures 2 and Figure 3).

\section{Results and discussion}

When analyzing the results, we verified that there is a higher prevalence of cases in which the offenders are the parents (60.6\%), being these framed with the typology that we chose to define as Indiscriminate (Cluster 2), since we found strong similarities with the characteristics of the subjects of the FBI child sex offenders typologies (Lanning, 1986, 2001, Lanning, 2010). 


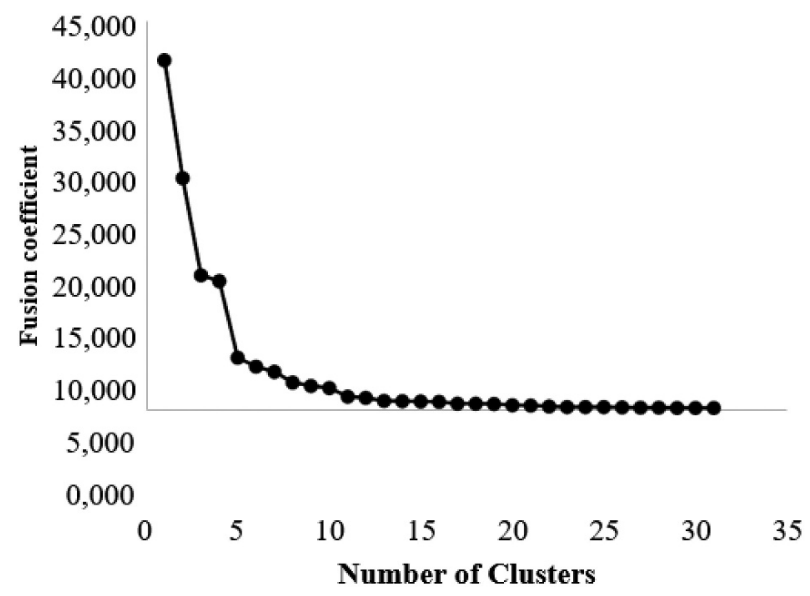

Figure 3. In this graph, referring to Hierarchical Cluster Analysis with Furthest Neighbor Method, there is a clear slope in the four clusters, validating the previous analysis.

However, our sample has no evident distinction between Morally Indiscriminate and Sexually Indiscriminate, so we decide on a unified perspective of a more comprehensive typology. Although the Lanning (2010) model conceives that the Sexually Indiscriminate abuse children outside their circle of relationships, what motivates them is the interest in sexual experimentation, seeking children out of boredom. We found a partial relationship with this Cluster, where subjects resort to several types of sexual stimulation (e.g., mutual masturbation, viewing pornography, nonpenetrating friction) but do not resort to children not under their sphere of trust. What clearly distinguishes this group is the search for sexual gratification, where the access does not result from a specific quest for replacing children with adults but preferably using the possibilities of success in their intentions. Resembling other authors (Groth \& Birnbaum, 1978; Soeiro, 2009), there is no evidence in this group of subjects belonging to a group of offenders with preferential interest in children. Thus, given the context of these subjects, we admit that the presence of deficits in selfcontrol and the practice of abuse as a crime of opportunity (Gottfredson \& Hirschi, 19901990) to achieve sexual gratification (Sullivan \& Beech, 2004; Ward et al., 2006) will be able to describe the central characteristics of the motivation of these subjects.

Within the scope of sexual practices specific to this group, there is a tendency for non-penetrative stimulation to occur (at an early stage) and may progress later to penetrating abuse that varies from oral and/or vaginal sex. Although there are fewer constraints on access to victims (such as those described by Finkelhor, 1984), due to family proximity and affective connection with them, we admit that the consolidation of access to minors, and the sexual practices that result from it, imply instilling 
normalization to these behaviors. Thus, a sexually more explicit and incisive action (out of the common) could retract the victim in an initial phase, making this process more difficult and increasing the possibility of being captured.

The results also reveal that these subjects turn a residual form of violence or threats. These outcomes are in line with the perspective that intra-familial offenders tend to be scoreless at the level of antisocial behavior and deviant sexual interests, compared to extra-familial sexual offenders (Marshall \& Barbaree, 1990; Ward \& Siegert, 2002; Seto, Babchischin, Pullman \& McPhail, 2015; Camperio Ciani et al., 2019).

Although the results verified the characteristics of the subjects serving a prison sentence in Portugal, international literature focuses on several theories that seek to explain this type of behavior (Abel et al., 1984; Ward, 2000; Ward \& Keenan, 1999). About the intrafamily offenders in our sample, some of their characteristics refer to the existence of deficits in terms of social skills (Hall \& Hirschman, 1992; Marshall \& Barbaree, 1990), low self-esteem (Marshall, Anderson \& Fernandez, 1999; Fernandez, Marshall, Lightbody \& O'Sullivan, 1999) and feelings of inadequacy (Robertiello \& Terry, 2007). At the same time, the presence of social and personal skills deficits, associated with looking sharp for sexual gratification (Sullivan \& Beech, 2003; Ward et al., 2006), allows this type of offender to hold the relationship privileged of trust and closeness with children (Lehmann et al., 2014; Terry \& Tallon, 2004), to commit this type of sexual crimes and which are associated with an Indiscriminate abuse profile (Lanning, 2010)

We also found that situations of intrafamily sexual abuse are those where there is a higher frequency of abuse, standing, in the limit, in daily or quasidaily abuse situations. In this sense, if we focus on aspects of the vulnerability of these victims through its age, we found that this aspect, associated with issues of developed and cognitive maturation, may condition their criminal investigation process, which tends ha to give the offender some feeling of impunity to act (Karkošková, 2015).

In this context, in addition to the beneficial and trusting relationship, there may be a life-long surrender of a position of power and/or dependence on the aggressor, which is not objectively coercive, is analyzed as having potential repercussions, in case the victim does not appear according to what it perceives as most appropriate. To this fact are added the natural barriers or gaps in communication, resulting from chronological age, which may, in a situation of investigation, create constraints in the collection of testimony (Karkošková, 2015). This increased exposure to sexual abuse by children is compatible with the number of cases reported to the authorities in Portugal, reaching more than twice [ 836 cases] of the situations perpetrated against adult victims [421 cases] (Sistema de Segurança Interna, 2018). 
Thus, the issue of credibility and discredit, associated with a position of power and dependence on the victim vis-à-vis an offending father, may lead to a chronic and repeated exposure of sexual abuse (; Brozowski \& Hall, 2010; Soares et al., 2010).

The second group with the most significant expression is represented by Cluster 1, where we find characteristics of aggression described by authors such as Regressed (Groth \& Birnbaum, 1978; Lehmann et al., 2014; Soeiro, 2009; Terry \& Tallon, 2004). These individuals tend to have deficits in coping strategies (Feelgood, Cortoni \& Thompson, 2005), easy access to victims, and use the child to substitute for sexual contact with adults (Lanning, 1984; Lanning, 2010).

In the case of our sample, although the parents are not the offenders, they are close relatives or people of close trust (Sullivan \& Beech, 2003; Ward et al., 2006). As Groth and Birnbaum (1978)described, these subjects tend not to resort to physical violence and seek only to obtain sexual gratification (Lanning, 2010). In this sample, we also found a tendency toward so-called conventional sexual behaviors, giving rise only to copulation, thus not showing more significant levels of interest in sexual exploitation, as Burgess et al. (1978) advocated or reinforced by Lehmann et al. (2014). It should be noted that given the characteristics associated with intra-family proximity, hypothetically, the description for Cluster 2 subjects will apply.

At the extra-family level, cluster 4 - Violent, presents itself as the one that includes more violent functioning patterns. In this context, offenders have a criminal history, where, similarly to other authors (Groth \& Burgess, 1977; Wortley \& Smallbone, 2006), criminal versatility is present and patterns of physical violence threats during and after abuse. If we analyze the etiological models of sexual aggression, this typology fits the combination of antisocial/ impersonal constellations and male hostility, consolidated by empathic deficits (e.g., Dean \& Malamuth, 1997; Malamuth et al., ; Malamuth, 1998).

Although these subjects tend to be more violent, when compared to the other groups, they can resort to gratification/enticement in order to overcome resistance to the consummation of the sexual act (Peckham, 2007), mainly because they are unknown to the victim and a more forceful action could trigger an immediate defense reaction on the part of the victim.

In Cluster 3, we found offenders who can be classified as Inadequate due to the similarity of the characteristics identified with other authors (Gannon et al., 2012; Lanning, 2010; Lehmann et al., 2014). Here, individuals with deficits in social and relational skills may include substance use or other types of mental disorders. In this group, the specific focus for children (e.g., paraphilia) may be present, and a higher incidence of cognitive distortions that guide their approach toward the victim (Ward \& Keenan, 1999; Ward, 2000; Ó Ciardha \& Ward, 2013). It is still important to emphasize that although there were, in some cases, suspicions of paraphilic focus (e.g., pedophilia), there 
were no differential diagnoses, which alone could have led to the decision to separate these subjects from the described group [which was not verified, as it was not the object of this study, to screen psychopathology].

In this group, we identified a history of previous convictions for sexual crimes and are unknown to the victims or just known without a previous relationship. We identified a similar pattern advocated by authors such as Groth et al. (1982)and Terry and Tallon (2004), where, in addition to what has been described, they tend not to have close relationships, appearing with apparent social and relational deficits. This group fits enough to those described by the FBI Typologies (Lanning, 2010), where they are described as unknown subjects of the victims, repeat offenders and with a potentially unusual pattern of sexual exploitation, this being the group where pedophiles can be identified, similar to the individuals in our sample.

Overall, we analyze the aggressive dynamics, but there is no recourse other than sexual assault ( $48.3 \%$ in our sample). These results may explain that in $78.8 \%$ of cases, someone committed a close relationship with the victims, specifically in the family context. The existence of violence generally tends to arise through an attempt to hide the crime committed or to create feelings of guilt among the victims (e.g., Groth \& Burgess, 1977).

Regarding penetrating sexual behavior, the exclusive vaginal penetration has the highest expression (30.3\%), occurring mainly in the case of Cluster 1, where it is clear the search of the offender by the substitution of an adult relationship and sex, which once again it appears to be framed with the characteristics of intrafamily abuse described in the reference literature (e.g., Groth \& Birnbaum, 1978; Terry \& Tallon, 2004; Soeiro, 2009; Lehman et al., 2014 ). In this group, there are cases where no previous stimulus/involvement has been described above. In a broader analysis of these typologies, referring to supplementary analysis variables, we found that in $12.1 \%$ of the cases, the victims had some previous mental pathology, which adds to their situation of vulnerability through age (Casteel, Martins, Smith, Gurka, and Kupper, 2008; Hughes et al., 2012; Basile, Breiding \& Smith, 2016). Although these numbers are not expressive, it is crucial to consider two hypotheses compared to the total number of cases analyzed. The first concerns the number of cases in which sentenced subjects serve suspended sentences (e.g., community work), and when they are absent from the prison sample, it does not allow us to understand their impact on these types. This hypothesis refers to the fact that in 2017 in Portugal, only 1/3 of the convicted individual have sentenced to prison (cf. Jornal Público, 2019, March 25). Contrary to what might be supposed, this it does not necessarily have a direct relationship with the seriousness of the crime, but rather with issues related to the fact that it is the first time that it has had contact with the justice system, showing regret, and being well socially framed. The second hypothesis refers to the black figures that may be conditioned by the credibility issues of the reports 
(Karkošková, 2015), where the advance to a criminal procedure, even in the cases that are known to the families, or the community, never reach move forward, for fear of seeing your loved ones being discredited.

The reduced number of convictions with reclusion punishment may generate a feeling of impunity. Nevertheless, since a more defined penal framework, the possibility of penal application tends to be often referred to as a solution for lack of evidence or denunciation. In this line, and possibly associated with this perspective of impunity, some studies relate sexual violence and condom use (e.g., O'Neal et al., 2013), that in our sample, in $96.3 \%$ of the analyzed cases, the subjects did not use it. Although there seems to be a relationship between alcohol consumption and not using condoms, this is not clear in our investigation. At the same time, it is important to contextualize that only $18 \%$ of the subjects admitted to or had a clinical history of alcohol consumption problems. If it is true that some of the subjects (e.g., Cluster 1Regressed typology) claim to have committed the crime under the influence of alcohol, the sentences analyzed in the proceedings do not confirm it and have not taken it for granted. Thus, it allows us to refer these arguments to the presence of cognitive distortions framed with the Implicit Theories (Ward \& Keenan, 1999), specifically with the legitimation of their behavior due to Uncountability.

However, in sexual violence against adults, alcohol consumption has a disinhibiting effect and deficits in self-control and impulsivity seem to be more solidly present [e.g., not using condoms]. In another perspective, some authors referring to child sex abuse tend to be mostly described as progressive (Lanning, 2010), reinforcing their confidence (Marshall \& Barbaree, 1990), causing resistance to drop (Finkelhor, Cuevas \& Drawbridge, Finkelhor et al., 2016)). So, we could explain $51.8 \%$ cases of ejaculation inside the victim or at least once [ejaculation inside the victim $=35.7 \%$; ejaculation inside and outside the victim $=16.1 \%]$. The ascendant over the victim, the controlling perception and the fact that the crime is mostly committed in a place that guarantees higher control of situation [home of the offender $=51.5 \%$; home of the victim and the aggressor $=36.5 \%]$, offender demonstrated deep concern about being caught, leading slowly to the reinforcement of their behavior.

Although the behaviors described and the frequency with which they tend to happen in the intrafamily context suggest a low probability of being caught, these aggressors, when identified, tend to assume different attitudes toward crime. In this research, we included a new variable, the admission of crimes and the offender's perspective evolution during the execution of the prison sentence [according to the evaluation of the prison services]. Of the four profiles identified, we found that the admission or ambivalence in their admission characterizes them in two of them. In the case of cluster 1Regressed, the offender tends to plead guilty. However, the information present in the cases refers to reduced or absent self-criticism, taking refuge repeatedly 
in the argument that they would be on the effect of alcohol (although alcohol intoxication has not been proven to trigger crime) (Cortoni \& Marshall, 2001; Fernandez \& Marshall, 2003).

On the other hand, extra-familial offenders, framed in Cluster 4 - Violent, have some polarity in admitting the crime, admitting, or denying it without reservation. The latter may be associated with antisocial characteristics (Dean \& Malamuth, 1997; Malamuth et al., ; Malamuth, 1998), was taking a position on crime may be linked to direct gains in its process, since when it occurs the admission of the crime, it is done without reservation, with self-criticism. However, it is unclear whether with some moral resonance or seeking to minimize or legitimize the behavior, which refers to deficits at the empathic level and the apparent apprehension of the crime.

We also found that when offenders admit to the crime, they tend to show greater self-criticism about the crime. Various authors have explored the relevance of cognition/perception about crime (e.g., Ward, 2000; Ward \& Keenan, 1999), and there are several models of sexual assault based on his assumptions, which is the most widely used approach for the intervention. In this sense, we understand the relationship between sexual attitudes and cognitive distortions as a future added value, confronting the nature of abusive behaviors perpetrated. Finally, we link the fact that, in the Model of four profiles presented, in two of them, the admission of crime contributes to the explanatory Model of this group, but there is no information about the content of the admission and the reported absence or reduced selfcriticism.

We decided on this model proposal with four different profiles with two groups (2x2), distinguished by the relationship with victims (see Table 6). Based on the identified elements, and using the FBI Child Molesters Profile Model (Lanning, 1986, 2001, Lanning, 2010) as a reference, we define four typologies with the following offender characteristics:

This work is a preliminary/exploratory study on the characteristics of CSA offenders in the Portuguese context. Although most international research focuses on motivations for aggression, there is still little knowledge about the patterns associated with CSA, particularly with the national context and data in southern Europe. Through ACM and CA, associated with the most widespread models of criminal profiles (e.g., Lanning, 1986, 2001, Lanning, 2010; Veenema, Thornton, \& Corley, Veenema et al., 2015; Chopin \& Caneppele, 2019; Camperio Ciani et al., 2019; Mathews \& Collin-Vézina, 2019), it was possible to identify four groups of offenders, divided by intrafamilial (Cluster 1 - Regressed; Cluster 2 - Indiscriminate) and extra-familial offenders (Cluster 3 - Inadequate; Cluster 4 - Violent). Although our reference model for data analysis is FBI Child Molesters Profile Model (Lanning, 1986, 2001, Lanning, 2010), it is essential to emphasize that. From the beginning of data collection, we found a clear division between intra and 
Table 6. Typologies of CSA proposed in our research.

\begin{tabular}{|c|c|c|c|}
\hline \multicolumn{2}{|c|}{ Type of offender } & \multirow{2}{*}{$\begin{array}{c}\% \\
18.2 \%\end{array}$} & \multirow[b]{2}{*}{$\begin{array}{l}\text { Offenders Characteristic's } \\
\text { Offenders target easily accessible victims. Although they had a close } \\
\text { familial relationship (stepfather and grandfather), parents are not } \\
\text { included in this type. } \\
\text { They prefer conventional sexual behavior without previously sexual } \\
\text { stimulation on abuse occurrence. The sexual dynamics of abuse are } \\
\text { vaginal and anal/vaginal penetration with ejaculation inside their } \\
\text { victims, and they claim that they consumed alcohol during or before } \\
\text { the abuse. When confronted with the crime, they admit, without, or } \\
\text { reduced self- criticism. Regarding the frequency of abuse, they } \\
\text { present multiple situations. }\end{array}$} \\
\hline $\begin{array}{l}\text { Intra } \\
\quad \text {-familial }\end{array}$ & $\begin{array}{l}\text { Regressed } \\
\text { (C1 -Cluster 1) }\end{array}$ & & \\
\hline & $\begin{array}{l}\text { Indiscriminate } \\
\text { (C2 -Cluster 2) }\end{array}$ & $60.6 \%$ & $\begin{array}{l}\text { Offenders are the victims' fathers and use the confidante relationship } \\
\text { to succeed in the abuse. In the leading cases, they do not resort to } \\
\text { aggression or threat to gain sexual gratification. They present } \\
\text { multiple non- penetrative dynamics such as masturbation and porn } \\
\text { preview or sexualized touch, including non-penetrating friction. In } \\
\text { several cases, penetration could not happen initially, then evolve to } \\
\text { oral sex and vaginal penetration. This offender does not have } \\
\text { criminal records but in some } \\
\text { cases could have domestic violence history. }\end{array}$ \\
\hline \multirow[t]{2}{*}{$\begin{array}{l}\text { Extra- } \\
\text { Familial }\end{array}$} & $\begin{array}{l}\text { Inadequate } \\
\text { (C3 -Cluster 3) }\end{array}$ & $1.51 \%$ & $\begin{array}{l}\text { These kinds of offenders have social misfits without an intimate partner } \\
\text { relationship. However, they have some relationship with the victims, } \\
\text { such as a neighbor, friend, or just a known person. They see these } \\
\text { relationships as a vehicle to explore their sexual interests, and in } \\
\text { some cases, could have mental illness diagnoses. They resort to } \\
\text { previous sexual stimulation and could fisting and/or introduce } \\
\text { objects to their victims. Concerning penetrative intercourse, they } \\
\text { opted for oral sex and anal penetration and resorted to various } \\
\text { aggressivity and threats. They have criminal records for sexual } \\
\text { crimes. }\end{array}$ \\
\hline & $\begin{array}{l}\text { Violent } \\
\qquad \text { (C4 -Cluster 4) }\end{array}$ & $19.7 \%$ & $\begin{array}{l}\text { Offenders are aggressive, with multiple records for crimes against } \\
\text { people and/or property history. They present the opposite position } \\
\text { about the crime, where they admit with self-criticism or non-admit } \\
\text { the crime. They could resort to other seductive strategies (e.g., } \\
\text { online seduction, grooming, and/or multiple gratifications). They } \\
\text { have aggressive and threatening behaviors to control their victims. } \\
\text { All offenders are unknown persons, and the abuse occurs on the } \\
\text { street or in vehicles. }\end{array}$ \\
\hline
\end{tabular}

extra-familial typologies. The use of violence and threats or seduction and gratification are present exclusively in the extra-familial, and the latter has representativeness lower than the first group. Thus, and similarly to the data reported by the Portuguese Annual Internal Security Report (Sistema de Segurança Interna, 2018), crimes committed in the intra-familial context have a higher expression when compared to the extra-familial ones, especially when dealing with cases in which the offenders are unknown to the victim. Nevertheless, we recognize the sample size as a limitation. Although the MCA technique does not provide a minimum number of cases for its analysis (cf. Di Franco, 2016), the benefit of a larger sample would be to improve the generalization of the results, and it may be interesting to include subjects who serve sentences without custody. 
Nevertheless, the Model with the proposal of typologies of child sexual abusers demonstrated distinguishing between groups. At the same time, in addition to the statistical results, descriptive and inferential results were obtained, which allowed framing the criminal profiles based on the characteristics of the actions taken. Kocsis (2009)emphasizes that this type of statistical analysis allows conceptual models with predictive validity, often presenting methodological limitations similar to those exposed here.

It allowed us to verify that the cognitive effort used in the justification/ legitimation of behaviors is strongly present in the subjects of our sample. Therefore, it is essential to consolidate its role when making a first approach to assessing individuals who sexually assaulted victims incapable of resistance, on which no literature supports, for example, the intervention in reducing recidivism.

Although the data obtained open new directions of research and consolidated the international literature in its transposition to the national context, there were some limitations related to the sample, more specifically, its characteristics and mode how they conditioned the use of other types of statistical tests, as they could confer more robustness to the conclusions presented. However, it is essential to emphasize that the results are still relevant since even though it has been obtained through several participants below what was initially intended, it proved to be significant.

Finally, in our view, this study contributes to more accurate and up-to-date knowledge about this crime in Portugal and Southern Europe. Therefore, in future goals, we believe that it is imperative to leading to a better understanding of the perspective of the subjects of the crime, according to the pattern of criminal behavior, trying to adjust increasingly incisive interventions based on national research, reducing the risk of bias in the use of data from other cultures/contexts.

\section{Acknowledgments}

The authors would like to acknowledge the assistance of the Portuguese General Office of Prison Services and Social Rehabilitation (Direção Geral de Serviços Prisionais e Reinserção Social) and the prison establishment where the study was conducted.

\section{Disclosure statement}

No potential conflict of interest was reported by the author(s).

\section{ORCID}

Ricardo Ventura Baúto (D) http://orcid.org/0000-0002-7255-2256

Jorge Cardoso (D) http://orcid.org/0000-0001-6037-3210 
Isabel Leal (D) http://orcid.org/0000-0002-1672-7912

\section{References}

Abdi, H., \& Valentin, D. (2007). Multiple correspondence analysis. In N. Salkind (Ed.), Encyclopedia of measurement and statistics(pp. 1-13). Sage Publications, Inc .

Abel, G. G., Becker, J. V., \& Cunningham-Rathner, J. (1984). Complications, consent, and cognitions in sex between children and adults. International Journal of Law and Psychiatry, 7 (1), 89-103. https://www.sciencedirect.com/science/article/abs/pii/0160252784900086?via\% 3Dihub

Abel, G. G., Gore, D. K., Holland, C. L., Camps, N., Becker, J. V., \& Rathner, J. (1989). The measurment of the cognitive distortions of child molesters. Annals of Sex Research, 2(2), 135-152. https://link.springer.com/article/10.1007\%2FBF00851319

Basile, K. C., Breiding, M. J., \& Smith, S. G. (2016). Disability and Risk of Recent Sexual Violence in the United States. American journal of public health, 106(5), 928-933. https:// doi.org/10.2105/AJPH.2015.303004

BBC News (2010, September 3) BBC News Online Retrieved December 21, 2019 from https:// www.BBC.com/news/world-Europe-11179026

Bennell, C., Alison, L., Stein, K., Alison, E., \& Canter, D. (2001). Sexual offenses against children as the abusive exploitation of conventional adult-child relationships. Journal of Social and Personal Relationships, 18(2), 155-171. https://doi.org/10.1177/ 0265407501182001

Brozowski, K., \& Hall, D. R. (2010). Aging and risk: Physical and sexual abuse of elders in Canada. Journal of Interpersonal Violence, 25(7), 1183-1199. https://doi.org/10.1177/ 0886260509340546

Burgess, A., Groth, N., Holmstrom, L., \& Sgroi, S. (1978). Sexual assault of children and adolescents. Lexington Books.

Camperio Ciani, A. S., Scarpazza, C., Covelli, V., \& Battaglia, U. (2019). Profiling acquired pedophilic behavior: Retrospective analysis of 66 Italian forensic cases of pedophilia. International Journal of Law and Psychiatry, 67 (2019) , 101508. https://doi.org/10.1016/j. ijlp.2019.101508

Canter, D., Hughes, D., \& Kirby, S. (1998). Paedophilia: Pathology, criminality, or both? The development of a multivariate model of offence behaviour in child sexual abuse. The Journal of Forensic Psychiatry, 9(3), 532-555. https://doi.org/10.1080/09585189808405372

Casteel, C., Martin, S. L., Smith, J. B., Gurka, K. K., \& Kupper, L. L. (2008). National study of physical and sexual assault among women with disabilities. Injury Prevention, 14(2), 87-90. https://doi.org/10.1136/ip.2007.016451

Chopin, J., \& Caneppele, S. (2019). Geocoding child sexual abuse: An explorative analysis on journey to crime and to victimization from French police data. Child Abuse \& Neglect, 91 (2019) , 116-130. https://doi.org/10.1016/j.chiabu.2019.03.001

Ciani, A. S., Scarpazza, C., Covelli, V., \& Battaglia, U. (2019). Profiling acquired pedophilic behavior: Retrospective analysis of 66 Italian forensic cases of pedophilia. International journal of law and psychiatry, 67, 101508. https://doi.org/10.1016/j.ijlp.2019.101508

Ciardha, C. Ó., \& Ward, T. (2013). Theories of cognitive distortions in sexual offending. Trauma, Violence \& Abuse, 14(1), 5-21. https://doi.org/10.1177/1524838012467856

Cohen, M., Seghorn, T., \& Calmas, W. (1969). Sociometric study of the sex offender. Journal of Abnormal Psychology, 74(2), 249-255. https://doi.org/10.1037/h0027185 
Cortoni, F., \& Marshall, W. L. (2001). Sex as a coping strategy and its relationship to juvenile sexual history and intimacy in sexual offenders. Sexual Abuse: Journal of Research and Treatment, 13(1), 27-43. https://doi.org/10.1177/107906320101300104

Dean, K. E., \& Malamuth, N. M. (1997). Characteristics of men who aggress sexually and of men who imagine aggressing: Risk and moderating variables. Journal of Personality and Social Psychology, 72(2), 449-455. https://doi.org/10.1037/0022-3514.72.2.449

Di Franco, G. (2016). Multiple correspondence analysis: One only or several techniques? Quality \& Quantity, 50(3), 1299-1315. https://doi.org/10.1007/s11135-015-0206-0

Feelgood, S., Cortoni, F., \& Thompson, A. (2005). Sexual coping, general coping and cognitive distortions in incarcerated rapists and child molesters. Journal of Sexual Aggression, 11(2), 157-170. https://doi.org/10.1080/13552600500073657

Fernandez, Y. M., \& Marshall, W. L. (2003). Victim Empathy, Social Self-Esteem, and Psychopathy in Rapists. Sexual Abuse, 15(1), 11-26. https://doi.org/10.1177/ 107906320301500102

Fernandez, Y. M., Marshall, W. L., Lightbody, S., \& O'Sullivan, C. (1999). The child molester empathy measure: description and examination of its reliability and validity. Sexual abuse : $a$ journal of research and treatment, 11(1), 17-31. https://doi.org/10.1177/ 107906329901100103

Finkelhor, D., Cuevas, C. A., \& Drawbridge, D. (2016). The four preconditions model. Boer, D. P. In The Wiley handbook on the theories, assessment and treatment of sexual offending (pp. 25-51). . John Wiley \& Sons Singapore Pte. Ltd.https://doi.org/10.1002/9781118574003. wattso002

Finkelhor, D. (1984). Child sexual abuse: New theory and research. Free Press.

Finkelhor, D. (1994). Current information on the scope and nature of child sexual abuse. The Future of Children/Center for the Future of Children, the David and Lucile Packard Foundation, 4(2), 31-53. https://doi.org/10.2307/1602522

Gannon, T., Terriere, R., \& Leader, T. (2012). Ward and Siegert's pathways model of child sexual offending: A cluster analysis evaluation. Psychology, Crime \& Law, 18(2), 129-153. https://doi.org/10.1080/10683160903535917

Goodwill, A. M., Alison, L. J., \& Beech, A. R. (2009). What works in offender profiling? A comparison of typological, thematic, and multivariate models. Behavioral Sciences \& the Law, 27(4), 507-529. https://doi.org/10.1002/bsl.867

Goodwill, A. M., Lehmann, R. J. B., Beauregard, E., \& Andrei, A. (2016). An action phase approach to offender profiling. Legal and Criminological Psychology, 21(2), 229-250. https:// doi.org/10.1111/lcrp.12069

Goodwill, A. M., Stephens, S., Oziel, S., Sharma, S., Allen, J. C., Bowes, N., \& Lehmann, R. (2013). Advancement of criminal profiling methods in faceted Multidimensional Analysis. Journal of Investigative Psychology and Offender Profiling, 10(1), 71-95. https://doi.org/10. 1002/jip. 1388

Goodwill, A., \& Alison, L. (2007). When is profiling possible? Offense planning and aggression as moderators in predicting offender age from victim age in stranger rape. Behavioral Sciences \& the Law, 25(6), 823-840. https://doi.org/10.1002/bsl.778

Gottfredson, M. G., \& Hirschi, T. (1990). A general theory of crime. Palo Alto, CA: Stanford University Press Green. (1990). A general theory of crime. Focus Autism Dev Disabil. 16. 72-85. doi:10.1177/108835760101600203

Groth, A. N., \& Birnbaum, H. J. (1978). Adult sexual orientation and attraction to underage persons. Archives of Sexual Behavior, 7(3), 175-181. https://doi.org/10.1007/BF01542377

Groth, A. N., \& Burgess, A. W. (1977). Motivational intent in the sexual assault of children. Correctional Psychologist, 4(3), 253-264. https://doi.org/10.1177/009385487700400303 
Groth, A. N., Hobson, W. F., \& Gary, T. S. (1982). THE CHILD MOLESTER:. Journal of Social Work \& Human Sexuality, 1(1-2), 129-144. https://doi.org/10.1300/J291v01n01_08

Hall, G. C. N., \& Hirschman, R. (1992). Sexual aggression against children. Criminal Justice and Behavior, 19(1), 8-23. https://doi.org/10.1177/0093854892019001003

Howells, K. (1994). Child sexual abuse: Finkelhor's precondition model revisited. Psychology, Crime \& Law, 1(3), 201-214. https://doi.org/10.1080/10683169508411956

Hughes, K., Bellis, M. A., Jones, L., Wood, S., Bates, G., Eckley, L., McCoy, E., Mikton, C., Shakespeare, T., \& Officer, A. (2012). Prevalence and risk of violence against adults with disabilities: a systematic review and meta-analysis of observational studies. Lancet (London, England), 379(9826), 1621-1629. https://doi.org/10.1016/S0140-6736(11)61851-5

Karkošková, S. (2015, june) Judicial Academy of the Slovak Republic - Seminar With in the Project Judiciary and Victims Protection, Omšenie

Knight, R. A., \& Prentky, R. A. (1990). Classifying sexual offenders: The development and corroboration of taxonomic models. In W. L. Marshall, D. R. Laws, and H. E. Barbaree (Eds.), Applied clinical psychology. Handbook of sexual assault: Issues, theories, and treatment of the offende (pp. 23-52). Plenum Press.

Knight, R. A., Rosenberg, R., and Schneider, B. (1985). Classification of sexual offenders: Perspectives, methods and validation. IN A. Burgess (Ed.), Rape and sexual assault: A research handbook. (pp. 222-293). New York: Garland Publishing.

Kocsis, R. N. (2009). Criminal profiling. In R. N. Kocsis (Ed.), Applied criminal psychology: A guide to forensic behavioral sciences (pp. 213-233)Charles C Thomas Publisher, Ltd.

Lanning, K. V. (1986). Child molesters: A behavioral analysis. Washington, DC: National Center for Missing \& Exploited Children.

Lanning, K. V. (2010). Child molesters: A behavioral analysis (5th ed (National Center for Missing \& Exploited Children).). https://www.icmec.org/wp-content/uploads/2015/10/USNCMEC-OJJDP-Child-Molesters-A-Behavioral-Analysis-Lanning-2010.pdf

Laws, D. R., \& Marshall, W. L. (2003). A brief history of behavioral and cognitive behavioral approaches to sexual offenders: Part 1. early developments. Sexual Abuse: A Journal of Research and Treatment, 15(2), 75-92. https://doi.org/10.1177/107906320301500201

Lehmann, R., Goodwill, A., Karl, H. R., \& Dahle, K.-P. (2014). Crime scene behaviors indicate risk-relevant propensities of child molesters. Criminal Justice and Behavior, 41(8), 1008-1028. https://doi.org/10.1177/0093854814521807

Liang, B., \& Hu, M. (2018). A typology of sex offending against minors: An empirical study of rape and molestation cases in China. Sexual Abuse, 30(8), 951-974. https://doi.org/10.1177/ 1079063217715017

Lyons, J., \& Romano, E. (2019). Childhood sexual abuse profiles and psychological functioning in adult males. Journal of Child Sexual Abuse, 28(5), 544-563. https://doi.org/10.1080/ 10538712.2018.1563263

Malamuth NM, Linz D, Heavey CL, Barnes G, and Acker M. (1995). Using the confluence model of sexual aggression to predict men's conflict with women: A 10-year follow -up study. Journal of Personality and Social Psychology, 69,353-369. doi:10.1037/00223514.69.2.353.

Malamuth, N. M., \& Heilmann, M. F. (1998). Evolutionary psychology and sexual aggression. In C. B. Crawford, and D. L. Krebs (Eds.), Handbook of evolutionary psychology: Ideas, issues, and applications (pp. 515-542). Lawrence Erlbaum Associates Publishers.

Marshall, W. L., \& Barbaree, H. E. (1990). An integrated theory of the etiology of sexual offending. In W. L. Marshall, D. R. Laws, and H. E. Barbaree (Eds.), Handbook of sexual assault. Applied Clinical Psychology. Springer. 257-275. 978-1-4899-0915-2. https://doi.org/ 10.1007/978-1-4899-0915-2_15 
Marshall, W.L., Anderson, D., \& Fernandez, Y., and Sullivan, J (1999). Cognitive behavioural treatament of sexual offenders. John Wiley \& Sons.

Mathews, B., \& Collin-Vézina, D. (2019). Child sexual abuse: Toward a conceptual model and definition. Trauma, Violence \& Abuse, 20(2), 131-148. https://doi.org/10.1177/ 1524838017738726

Mohr, J. W. , Turner, R. E. , \& Jerry, M. B. (1964). Pedophilia and exhibitionism. Toronto: University of Toronto Press.

O’Neal, E., Decker, H., Spohn, C., \& Tellis, K. (2013). Condom use during sexual assault. Journal of Forensic and Legal Medicine, 20(6), 605-609. https://doi.org/10.1016/j.jflm.2013. 03.023

Peckham, N. G. (2007). The vulnerability and sexual abuse of people with learning disabilities. British Journal of Learning Disabilities, 35(2), 131-7. https://doi.org/10.1111/j.14683156.2006.00428.x

Rebocho, M. F., \& Gonçalves, R. A. (2012). Sexual predators and prey. Journal of Interpersonal Violence, 27(14), 2770-2789. https://doi.org/10.1177/0886260512438280

Robertiello, G., \& Terry, K. J. (2007). Can we profile sex offenders? A review of sex offender typologies. Aggression and Violent Behavior, 12(5), 508-518. https://doi.org/10.1016/j.avb. 2007.02.010

Safarik, J. P., Jarvis, M. E., \& Nussbaum, K. E. (2002). Sexual homicide of elderly females linking offender characteristics to victim and crime scene attributes. Homicide of Elderly Females: Society of Criminology Meetings, 17(5). https://doi.org/10.1177/ 0886260502017005002

Salerno, L. M. (2014). A structural examination of integrative theories of sexual offending and reoffending. Ruthers, The State University of New Jersey, New Jersey.

Saramago, M. A., Cardoso, J., \& Leal, I. (2020). Victim crossover index offending patterns and predictors in a portuguese sample. Sexual Abuse, 32(1), 101-124. https://doi.org/10.1177/ 1079063218800472

Scarpazza, C., Pellegrini, S., Pietrini, P., \& Sartori, G. (2018). The role of neuroscience in the evaluation of mental insanity: On the controversies in Italy: Comment on "On the stand. Another episode of neuroscience and law discussion from Italy". Neuroethics, 11(1), 83-95. https://doi.org/10.1007/s12152-017-9349-0

Schaaf, S., Jeglic, E. L., Calkins, C., Raymaekers, L., \& Leguizamo, A. (2019). Examining ethno-racial related differences in child molester typology: An MTC:CM3 approach. Journal of Interpersonal Violence, 34(8), 1683-1702. https://doi.org/10.1177/ 0886260516653550

Seto, M. C., Babchishin, K. M., Pullman, L. E., \& McPhail, I. V. (2015). The puzzle of intrafamilial child sexual abuse: a meta-analysis comparing intrafamilial and extrafamilial offenders with child victims. Clinical psychology review, 39, 42-57. https://doi.org/10.1016/j. cpr.2015.04.001

Simon W, and Gagnon JH.(1986). Sexual scripts: permanence and change. Arch Sex Behav, 15 (2),97-120. doi: 10.1007/BF01542219. PMID: 3718206.

Sistema de Segurança Interna. (2018). Relatório Anual de Segurança Interna. www.otsh.mai. gov.pt/wp-content/uploads/RASI-2018.pdf

Soares J., Barros H. Torres-Gonzales, F. Ioannidi-Kapolou, E. Lamura, and G. LindertJ., J G (2010). Abuse and health in Europe. Kaunas: Lithuanian University of Health Sciences Press.

Soeiro, C. (2009). Perfis criminais e crime de abuso sexual de crianças: Caracterização de uma tipologia para a realidade portuguesa. Ousar Integrar - Revista de Reinserção Social E Prova, 2 (4), 1-15. 
Stephens, S., Seto, M. C., Goodwill, A. M., \& Cantor, J. M. (2018). The relationships between victim age, gender, and relationship polymorphism and sexual recidivism. Sexual Abuse: A Journal of Research and Treatment, 30(2), 132-146. https://doi.org/10.1177/ 1079063216630983

Sullivan, J. , \& Beech, A. (2003). Are collectors of child abuse images a risk to children? In A. MacVean, and P. Spindler (Eds.) Policing pedophiles on the internet (pp. 11-20). England UK: The New Police Bookshop.

Sullivan, J, and Beech, A. (2004). A comparative study of demographic data relating to intra and extra-familial child sexual abusers and professional perpetrators. Journal of Sexual Aggression, 10, 39-50. doi:10.1080/13552600410001667788.

Terry K. J. (2006). Sexual offenses and offenders: Theory, practice and policy. Wadsworth, Belmont, CA.

Terry, K. J., \& Tallon, J. (2004). Child sexual abuse: A review of the literature. John Jay College. 148. https://www.ojp.gov/ncjrs/virtual-library/abstracts/child-sexual-abuse-reviewliterature

Veenema, T. G., Thornton, C. P., \& Corley, A. (2015). The public health crisis of child sexual abuse in low and middle income countries: An integrative review of the literature. International Journal of Nursing Studies, 52(4), 864-881. https://doi.org/10.1016/j.ijnurstu. 2014.10.017

Ward, T., and Beech, A. R. (2016). The Integrated Theory of Sexual Offending-Revised. In Boer, D. P. (Eds.), Theories, Assessment, and Treatment of Sexual Offending (pp. 123-137). John Wiley.

Ward, T., \& Beech, A. (2006). An integrated theory of sexual offending. Aggression and Violent Behavior, 11(1), 44-63. https://doi.org/10.1016/j.avb.2005.05.002

Ward, T., \& Hudson, S. M. (2001). Finkelhor's precondition model of child sexual abuse: A critique. Psychology, Crime \& Law, 7(4), 291-307. https://doi.org/10.1080/ 10683160108401799

Ward, T., \& Keenan, T. (1999). Child molesters' implicit theories. Journal of Interpersonal Violence, 14(8), 821-838. https://doi.org/10.1177/088626099014008003

Ward, T., Polaschek, D. L. L., \& Beech, A. R. (2006). Theories of sexual offending. (U. of L. Holin, Clive R. (Clinical Division of Psychiatry \& C. U. McMurran, Mary (School of Psychology, Eds.). Wiley.

Ward, T., \& Siegert, R. J. (2002). Toward a comprehensive theory of child sexual abuse: A theory knitting perspective. Psychology, Crime \& Law, 8(4), 319-351. https://doi.org/10. $1080 / 10683160208401823$

Ward, T. (2000). Sexual offenders' cognitive distortions as implicit theories. Aggression and Violent Behavior, 5(5), 491-507. https://doi.org/10.1016/S1359-1789(98)00036-6

Ward, T. (2009). The extended mind theory of cognitive distortions in sex offenders. Journal of Sexual Aggression, 15(3), 247-259. https://doi.org/10.1080/13552600903263087

Waterhouse, G. F., Reynolds, A., \& Egan, V. (2016). Myths and legends: The reality of rape offences reported to a UK police force. The European Journal of Psychology Applied to Legal Context, 8(1), 1-10. https://doi.org/10.1016/j.ejpal.2015.04.001

World Health Organization. (1999). . Report of the Consultation on Child Abuse Prevention. Geneva: WHOAccessedMarch 2020. apps.who.int/iris/handle/10665/65900

Wortley, R., \& Smallbone, S . (2006). Applying situational principles to sexual offenses against children). Crime prevention studies, 19, 7-35 . www.researchgate.net/publication/29462196 